\title{
Serial optical coherence tomography imaging of ACS-causing culprit plaques
}

Géraud Souteyrand ${ }^{1}$, MD; Eloisa Arbustini², MD; Pascal Motreff ${ }^{1}$, MD; Laura Gatto ${ }^{3,4}$, MD; Luca Di Vito ${ }^{4}$, MD; Valeria Marco ${ }^{4}$, BAN; Nicolas Amabile 5 , MD; Alberto Chisari ${ }^{4}, \mathrm{MD}$; Takhaide Kodama ${ }^{2}$, MD;

Enrico Romagnoli ${ }^{4}$, MD; Luigi Tavazzi ${ }^{6}$, MD; Filippo $\mathrm{Crea}^{7}$, MD; Jagat Narula ${ }^{8}$, MD; Francesco Prati ${ }^{3,4}$, MD

1. Department of Cardiology, Clermont-Ferrand University Hospital, Clermont-Ferrand, France, 2. Centre for Inherited Cardiovascular Diseases, Fondazione IRCCS Policlinico San Matteo, Pavia, Italy; 3. Department of Cardiology, San Giovanni Addolorata Hospital, Rome, Italy; 4. Centro per la Lotta contro l'Infarto - CLI Foundation, Rome, Italy; 5. CCML PlessisRobinson, Marie Lannelongue Surgical Center, Le Plessis Robinson, France; 6. Maria Cecilia Hospital-GVM Care and Research, E. S. Health Science Foundation, Cotignola, Italy; 7. Catholic University of Sacred Heart, Rome, Italy; 8. The Mount Sinai Medical Center, New York, NY, USA

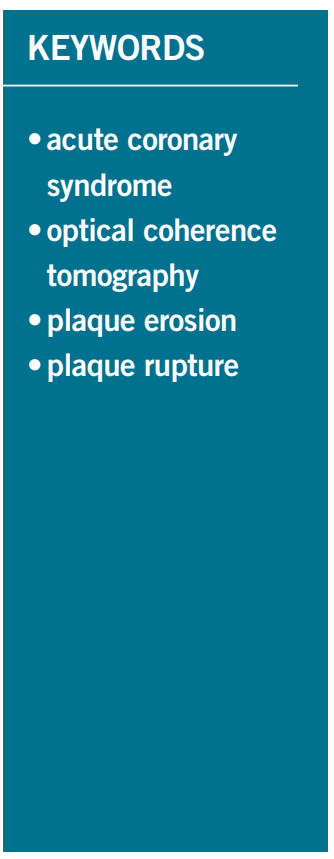

\section{Abstract}

Aims: The aim of this study was to understand better the mechanisms of repair of plaque complications causing acute coronary syndrome.

Methods and results: We used OCT in the acute phase and at follow-up (one to seven months) to investigate the plaque healing in 10 culprit plaques: five ruptured fibrous cap (RFC) and five intact fibrous cap (IFC) which were not treated with stent deployment and caused ST-segment elevation myocardial infarction $(n=8)$ and non-STEMI $(n=2)$. At follow-up OCT, the margins of the evacuated cavity in RFC plaques showed a smooth surface and a morphology similar to that of baseline images, while IFC plaques showed a smoothened intimal border and a double layering indicating organising thrombus incorporated in the superficial layers of the plaque.

Conclusions: In the months following a successfully dissolved acute thrombosis, OCT revealed that the cavity of RFC plaques persists and is bordered by a smooth "neointima", while IFC plaques showed features suggesting partial incorporation of the deepest layers of thrombus in the plaque.

\footnotetext{
*Corresponding author: Interventional Cardiology, San Giovanni Hospital, Via dell'Amba Aradam, 8, 00184 Rome, Italy. E-mail:fprati@hsangiovanni.roma.it
} 


\section{Introduction}

The natural history of culprit plaques, both with a ruptured fibrous cap (RFC) and with an intact fibrous cap (IFC), causing an acute coronary syndrome (ACS) has not been systematically investigated in vivo ${ }^{1}$. In 10 patients with ACS, we used serial optical coherence tomography (OCT) to explore the repair and healing morphology of non-critically narrowed culprit plaques, both with RFC and IFC, which were treated with thrombus aspiration or systemic thrombolysis alone without angioplasty or stent implantation.

\section{Methods}

This is a hypothesis-generating prospective study which was performed using 10 patients with ACS (Table 1). Twenty-five patients with ACS were scrutinised over four months. Ten fulfilled the following criteria of enrolment: onset of symptoms $<12$ hours, achievement of "optimal reperfusion" with a Thrombolysis In Myocardial Infarction (TIMI) 3 flow with non-critical residual angiographic narrowing, and a small plaque/thrombus prolapse on $\mathrm{OCT}^{2}$, after thrombus aspiration or thrombolysis. Seven patients received thrombus aspiration, two were treated with IV abciximab and one with systemic thrombolysis (Table 2). Baseline OCT study of culprit lesions was obtained after 5.2 \pm 2.6 days, whilst the follow-up OCT study was repeated at a time point between one and seven months. Patient characteristics and procedural details are described in Table 1 and Table 2.

All procedures were performed according to the current guidelines. Patients received aspirin, thienopyridine, and unfractionated heparin (5,000-10,000 IU) (Table 2). After discharge, patients underwent coronary angiogram and OCT assessments as per local practice. The repeat angiogram with OCT was done at two, four, six and seven months in four, one, four and one patient, respectively. Written informed consent was obtained before follow-up angiographic OCT procedures that were deemed clinically useful.

Coronary angiograms were analysed off-line using quantitative coronary angiography (QCA) $)^{3}$.

The OCT culprit lesion morphology was described according to previously reported criteria ${ }^{2,4,5}$.

\section{Statistical analysis}

Continuous variables are reported as mean (standard deviation) and were compared with the Student's t-test, while categorical variables are reported as n (\%) and were compared using Fisher's exact test. Statistical significance was set at the two-tailed 0.05 level.

\section{Table 1. Patient characteristics.}

ID Gender Age Diabetes Dyslipidaemia Hypertension Smoker

\begin{tabular}{|c|c|c|c|c|c|c|c|c|c|c|c|c|c|}
\hline ID & Gender & Age & Diabetes & Dyslipidaemia & Hypertension & Smoker & $\begin{array}{c}\text { Family } \\
\text { history }\end{array}$ & $\begin{array}{c}\text { Prior } \\
\text { MI }\end{array}$ & $\begin{array}{c}\text { Prior } \\
\text { PCI }\end{array}$ & $\begin{array}{c}\text { LVEF } \\
\text { (\%) }\end{array}$ & $\begin{array}{c}\text { Clin. } \\
\text { syndr. }\end{array}$ & $\begin{array}{c}\text { Culprit } \\
\text { lesion }\end{array}$ & $\begin{array}{c}\text { n. diseased } \\
\text { vessels }\end{array}$ \\
\hline 1 & M & 45 & N0 & YES & N0 & N0 & N0 & YES & YES & 55 & STEMI & LAD & 2 \\
\hline 2 & M & 51 & N0 & N0 & N0 & N0 & N0 & YES & N0 & 67 & STEMI & LAD & 1 \\
\hline 3 & M & 37 & N0 & N0 & N0 & YES & YES & N0 & N0 & 48 & STEMI & LAD & 1 \\
\hline 4 & M & 24 & N0 & YES & N0 & YES & N0 & N0 & N0 & 50 & STEMI & LAD & 1 \\
\hline 5 & M & 43 & YES & N0 & N0 & YES & N0 & N0 & N0 & 62 & NSTEMI & RCA & 1 \\
\hline 6 & M & 71 & N0 & N0 & N0 & YES & N0 & N0 & N0 & 45 & NSTEMI & LAD & 1 \\
\hline 7 & M & 35 & N0 & YES & N0 & YES & N0 & N0 & N0 & 50 & STEMI & LAD & 1 \\
\hline 8 & M & 42 & N0 & YES & N0 & N0 & YES & N0 & N0 & 50 & STEMI & RCA & 1 \\
\hline 9 & M & 66 & N0 & YES & YES & YES & N0 & N0 & N0 & 70 & STEMI & LAD & 2 \\
\hline 10 & M & 21 & N0 & N0 & N0 & YES & N0 & N0 & N0 & 40 & STEMI & LAD & 1 \\
\hline
\end{tabular}

Clin. syndr: clinical syndrome; LAD: left anterior descending; LVEF: left ventricular ejection fraction; NSTEMI: non-ST-elevation myocardial infarction; RCA: right coronary artery; STEMI: ST-elevation myocardial infarction

Table 2. Procedural details.

\begin{tabular}{|c|c|c|c|c|c|c|c|c|c|c|}
\hline ID & $\begin{array}{c}\text { Systemic } \\
\text { thrombolysis }\end{array}$ & $\begin{array}{l}\text { Thrombus } \\
\text { asp. device }\end{array}$ & $\begin{array}{l}\text { Ilb/llla } \\
\text { inhib. }\end{array}$ & $\begin{array}{l}\text { ADP } \\
\text { antag. }\end{array}$ & $\begin{array}{c}\text { Basal DS } \\
(\%)\end{array}$ & $\begin{array}{c}\text { Post-interv. } \\
\% \text { DS }\end{array}$ & $\begin{array}{c}\text { Basal TIMI } \\
\text { flow }\end{array}$ & $\begin{array}{l}\text { Post-interv. } \\
\text { TIMI flow }\end{array}$ & $\begin{array}{l}\text { Tot. isch. } \\
\text { time (hours) }\end{array}$ & $\begin{array}{l}\text { Clinical } \\
\text { syndrome }\end{array}$ \\
\hline 1 & NO & YES & YES & PRASUGR & 100 & 46 & 0 & III & 2 & STEMI \\
\hline 2 & NO & YES & YES & CLOPID & 100 & 40 & 0 & III & 1 & STEMI \\
\hline 3 & YES & NO & NO & CLOPID & 53 & 20 & II & III & 3 & STEMI \\
\hline 4 & NO & YES & YES & PRASUGR & 90 & 33 & 1 & III & 1.5 & STEMI \\
\hline 5 & NO & YES & YES & PRASUGR & 78 & 41 & 1 & III & 12 & NSTEMI \\
\hline 6 & NO & NO & YES & PRASUGR & 53 & 25 & $\|$ & III & 2.5 & NSTEMI \\
\hline 7 & NO & NO & YES & PRASUGR & 45 & 30 & II & III & 1.5 & STEMI \\
\hline 8 & NO & YES & NO & PRASUGR & 92 & 22 & 1 & III & 1.5 & STEMI \\
\hline 9 & NO & YES & YES & PRASUGR & 59 & 23 & II & III & 2.5 & STEMI \\
\hline 10 & NO & YES & YES & PRASUGR & 95 & 43 & 1 & III & 13 & STEMI \\
\hline
\end{tabular}




\section{Results}

Eight patients had an ST-elevation myocardial infarction (STEMI), and the remaining two patients suffered a non-ST-elevation myocardial infarction (NSTEMI). Of the eight patients with STEMI, thrombus aspiration was performed in six, systemic thrombolysis in one, and the remaining patient was treated only with IV abciximab. Of the two patients with NSTEMI, one was treated with thrombus aspiration and one with IV abciximab (Table 1, Table 2).

\section{Pre- and post-intervention plaque morphology}

The mean total ischaemic time was $2.9 \pm 3.5$ hours; baseline angiography is described in Table 2. The pre-intervention MLD and RVD were $0.30 \pm 0.42 \mathrm{~mm}$ and $3.2 \pm 0.45 \mathrm{~mm}$, respectively.

Thrombus aspiration $(n=7)$ or medical therapy $(n=3)$ led to a mild residual diameter stenosis with final TIMI 3 flow in all cases.

Baseline OCT assessment of culprit lesions demonstrated RFC in five patients and IFC in the remaining five patients, with OCT aspects of thrombosis being revealed in all cases.

\section{Follow-up plaque morphology and clinical outcome}

Angiography confirmed the presence of a TIMI 3 flow in all cases without significant luminal compromise. The morphology on OCT of the five culprit lesions with RFC did not change during follow-up (Table 3) with all lesions showing clear communication between the plaque cavity and the lumen (Figure 1), both early (one to two months after the baseline assessment) and late (four and six months). Fibrous cap thickness, minimal lumen area and mean lumen area remained unchanged during followup $(+12.7 \%, \mathrm{p}=\mathrm{ns} ;-1.56 \% \mathrm{p}=\mathrm{ns}$ and $-0.10 \% \mathrm{p}=\mathrm{ns}$, respectively). The quantitative measurements of the longitudinal and circumferential extension of the cavity also remained unchanged (Table 4). New tissue apposition (neointima-like) was seen to develop at follow-up.

The morphology of the IFC changed over time. The irregular inner border of the thrombus in the acute phase evolved to a homogeneous and smooth profile in all OCT cross-sections of the four cases that were serially imaged after at least 42 days (Table 3). On the other hand, the images of the patient who was followed up at 28 days were similar to the baseline morphology (Figure 2). At follow-up, the organised thrombus showed a rim of circumferential transition exhibiting a low backscatter (neointima) in all of the cross-sections (Figure 2). In the five patients with IFC, a non-significant reduction in minimal and mean lumen area was observed ( -8.5 and -9.9 percent, respectively).

During a mean clinical follow-up of $26.9 \pm 10.4$ months (range one to four years), all 10 patients have remained asymptomatic and have not developed further acute cardiovascular events.

\section{Discussion}

This hypothesis-generating serial OCT study addresses the natural history of the evolution of plaque morphology of non-critically narrowed culprit lesions both with RFC and IFC in patients
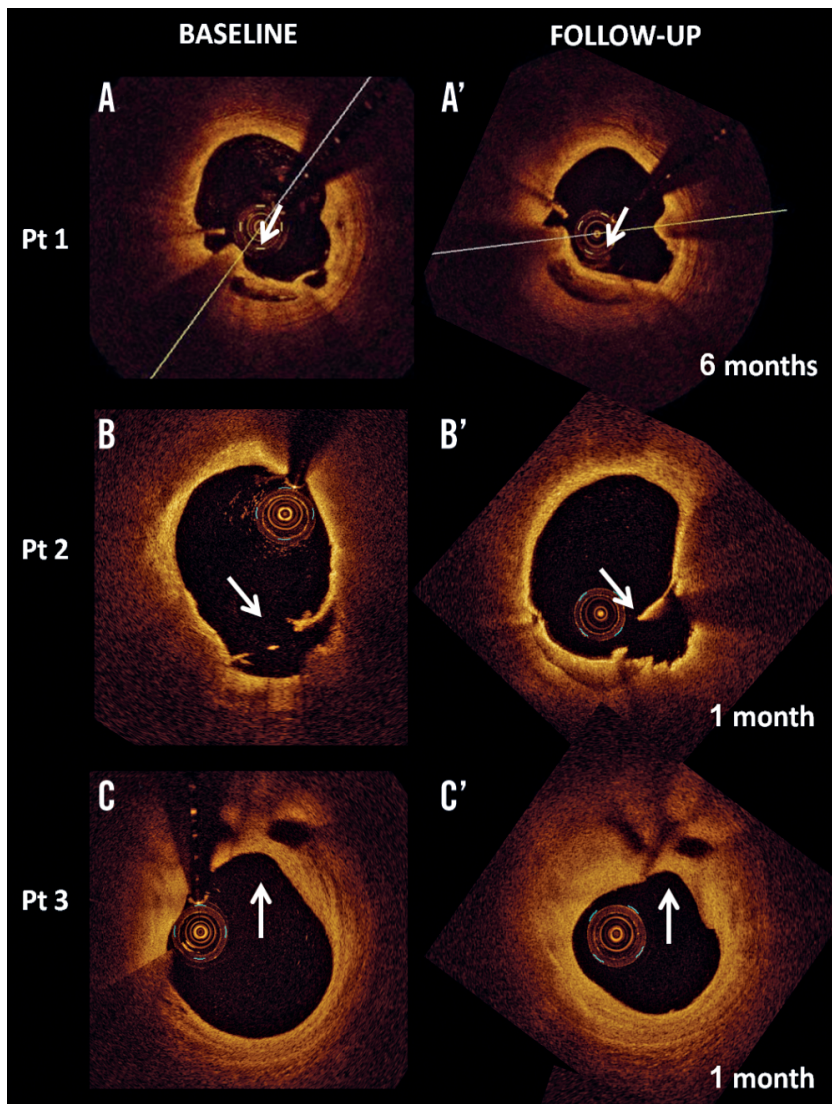

D

D'

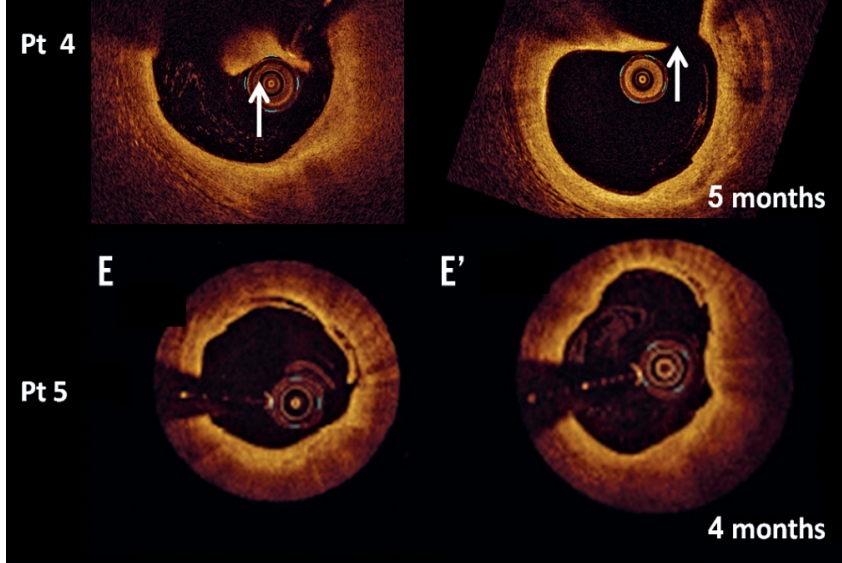

Figure 1. OCT assessment of culprit lesions with ruptured fibrous cap (RFC) at baseline and inherent changes over time. A-A' and $B-B$ '. Examples of culprit lesions with RFC (arrows in the left panel) exhibiting a clear communication between the inner (necrotic) core of the plaque and the lumen. Plaque morphology is unchanged at follow-up from the acute event with plaque ulceration still visible (arrow in the right panels). C-C'. The presence of RFC can be seen at follow-up. In this case the lumen gets smaller probably due to a process of organisation of the thrombus remnants. $D-D$ '. Plaque ulceration imaged just proximal to a lipid pool. The sign of plaque rupture can be seen at follow-up. Please note that the presence of thrombus on the fibrous cap hampers the clear visualisation of the cavity in the acute phase. E-E'. A superficial plaque dissection can be seen in the acute phase (left panel) and at follow-up (right panel). 
Table 3. OCT qualitative analysis.

\begin{tabular}{|c|c|c|c|c|c|c|c|}
\hline \multirow[b]{2}{*}{ ID } & \multirow{2}{*}{$\begin{array}{c}\text { Mechanism of } \\
\text { plaque instability }\end{array}$} & \multicolumn{3}{|c|}{ Acute/subacute assessment } & \multicolumn{3}{|c|}{ Follow-up assessment } \\
\hline & & $\begin{array}{l}\text { OCT time point } \\
\text { after AMI (days) }\end{array}$ & $\begin{array}{l}\text { Thrombus } \\
\text { detection }\end{array}$ & $\begin{array}{l}\text { Culprit lesion } \\
\text { with RFC }\end{array}$ & $\begin{array}{l}\text { OCT time point } \\
\text { after AMI (days) }\end{array}$ & $\begin{array}{l}\text { Organised } \\
\text { thrombus }\end{array}$ & $\begin{array}{l}\text { Culprit lesion } \\
\text { with RFC }\end{array}$ \\
\hline 1 & IFC & 1 & YES & NO & 28 & YES & NO \\
\hline 2 & IFC & 3 & YES & NO & 187 & YES & NO \\
\hline 3 & IFC & 8 & YES & NO & 160 & YES & NO \\
\hline 4 & IFC & 2 & YES & NO & 183 & YES & NO \\
\hline 5 & IFC & 4 & YES & NO & 42 & YES & NO \\
\hline 6 & RFC & 8 & YES & YES & 205 & YES & YES \\
\hline 7 & RFC & 5 & YES & YES & 41 & NO & YES \\
\hline 8 & RFC & 6 & YES & YES & 33 & YES & YES \\
\hline 9 & RFC & 7 & YES & YES & 177 & YES & YES \\
\hline 10 & RFC & 8 & YES & YES & 116 & YES & YES \\
\hline
\end{tabular}

Table 4. Quantitative OCT analysis.

\begin{tabular}{|c|c|c|c|c|c|c|c|c|c|c|c|c|c|}
\hline \multirow[b]{2}{*}{ ID } & & \multicolumn{4}{|c|}{ Acute phase } & \multicolumn{4}{|c|}{ Follow-up } & \multicolumn{4}{|c|}{ Difference } \\
\hline & & $\begin{array}{l}\text { MLA } \\
\mathrm{mm}^{2}\end{array}$ & $\begin{array}{c}\text { Mean LA } \\
\mathrm{mm}^{2}\end{array}$ & $\begin{array}{c}\text { FC thick } \\
\text { Im }\end{array}$ & $\begin{array}{c}\text { LP } \\
\text { Arc }^{\circ}\end{array}$ & $\begin{array}{l}\text { MLA } \\
\mathrm{mm}^{2}\end{array}$ & $\begin{array}{c}\text { Mean LA } \\
\mathrm{mm}^{2}\end{array}$ & $\begin{array}{c}\text { FC thick } \\
\text { Im }\end{array}$ & $\begin{array}{l}\text { LP } \\
\text { Arc }^{\circ}\end{array}$ & $\begin{array}{l}\text { MLA } \\
\mathrm{mm}^{2}\end{array}$ & $\begin{array}{c}\text { Mean LA } \\
\mathrm{mm}^{2}\end{array}$ & $\begin{array}{c}\text { FC thick } \\
\text { Im }\end{array}$ & $\begin{array}{c}\text { LP } \\
\text { Arc }^{\circ}\end{array}$ \\
\hline 1 & IFC & 6.33 & 9.95 & 160 & 210 & 4.6 & 7.74 & 160 & 210 & 1.73 & 2.21 & 0 & 0 \\
\hline 2 & IFC & 7.16 & 8.94 & 0 & 0 & 5.92 & 8.75 & 0 & 0 & 1.24 & 0.19 & 0 & 0 \\
\hline 3 & IFC & 2.36 & 3.75 & 120 & 208 & 1.9 & 3.27 & 120 & 190 & 0.46 & 0.48 & 0 & 18 \\
\hline 4 & IFC & 5.62 & 7.52 & 140 & 92 & 5.92 & 7.17 & 135 & 75 & -0.30 & 0.35 & 5 & 17 \\
\hline 5 & IFC & 2.77 & 6.09 & 0 & 0 & 3.85 & 5.72 & 0 & 0 & -1.08 & 0.37 & 0 & 0 \\
\hline & Mean & 4.85 & 7.25 & 84.00 & 102.00 & 4.44 & 6.53 & 83.00 & 95.00 & 0.41 & 0.72 & 1.00 & 7.00 \\
\hline & STD & 2.16 & 2.44 & 77.97 & 104.65 & 1.67 & 2.13 & 77.10 & 100.87 & 0.49 & 0.31 & 0.87 & 3.78 \\
\hline 6 & RFC & 5.62 & 7.73 & 40 & 245 & 5.92 & 7.42 & 45 & 250 & -0.30 & 0.31 & -5.00 & -5.00 \\
\hline 7 & RFC & 6.86 & 9.12 & 40 & 306 & 6.82 & 9.69 & 61 & 258 & 0.04 & -0.57 & -21.00 & 48.00 \\
\hline 8 & RFC & 4.85 & 6.7 & 70 & 200 & 3.47 & 5.5 & 75 & 200 & 1.38 & 1.20 & -5.00 & 0.00 \\
\hline 9 & RFC & 7.01 & 10.25 & 88 & 220 & 7.46 & 13.13 & 90 & 220 & -0.45 & -2.88 & -2.00 & 0.00 \\
\hline 10 & RFC & 4.49 & 6.59 & 69 & 180 & 4.71 & 4.61 & 75 & 170 & -0.22 & 1.98 & -6.00 & 10.00 \\
\hline & Mean & 5.77 & 8.08 & 61.40 & 230.20 & 5.68 & 8.07 & 69.20 & 219.60 & 0.09 & 0.01 & -7.80 & 10.60 \\
\hline & STD & 1.14 & 1.58 & 20.95 & 48.74 & 1.61 & 3.44 & 16.98 & 36.20 & -0.46 & -1.85 & 3.97 & 12.53 \\
\hline
\end{tabular}

LA: Iumen area; LP: lipid pool; FC: fibrous cap; IFC: intact fibrous cap; MLA: minimal lumen area; RFC: ruptured fibrous cap; STD: standard deviation

presenting with ACS. OCT images showed that the plaque cavity which is the marker of culprit lesions with RFC may remain open several months after an acute coronary event. The border of the cavity may appear smoother as compared to the acute phase, suggesting a superficial healing process with the growth of a neointimal layer. OCT images in IFC plaques, wherein the cavity is typically absent, show the presence of a two- (or more) layer structure with low backscatter inner rim(s) of circumferential transition from the surface to original plaque. This suggests that the layer of residual thrombotic material is probably incorporated in the plaque and shows a neointimal-like evolution. The plaque demonstrates a slight increase of the intraluminal burden. At a short to mid interval from the acute event, plaques which caused local occlusive thrombosis (thrombogenic plaques) show the OCT morphological features of stable plaques.
Most knowledge on coronary lesion development, progression and complications is based on histopathology studies, which provide a single time point profile of the coronary pathology ${ }^{6}$. Intravascular imaging offers the unique opportunity of interrogating coronary plaques during serial studies, thus potentially addressing research on plaque changes and evolution in vivo ${ }^{4}$. Studies aimed at assessing plaque instability in the coronary tree of patients with $\mathrm{ACS}^{7,8}$ have identified multiple complex lesions but did not prove the simultaneous destabilisation of more than one plaque. Disruption of multiple plaques reflects a diffuse or multifocal coronary instability, a well-established concept which rests on both post-mortem data $^{6}$ and biomarker studies demonstrating widespread inflammation ${ }^{9}$. What is still unknown is the time lapse between the rupture of a plaque and its healing and whether healed plaques can be considered as clinically stable and non-thrombogenic. The studies which 


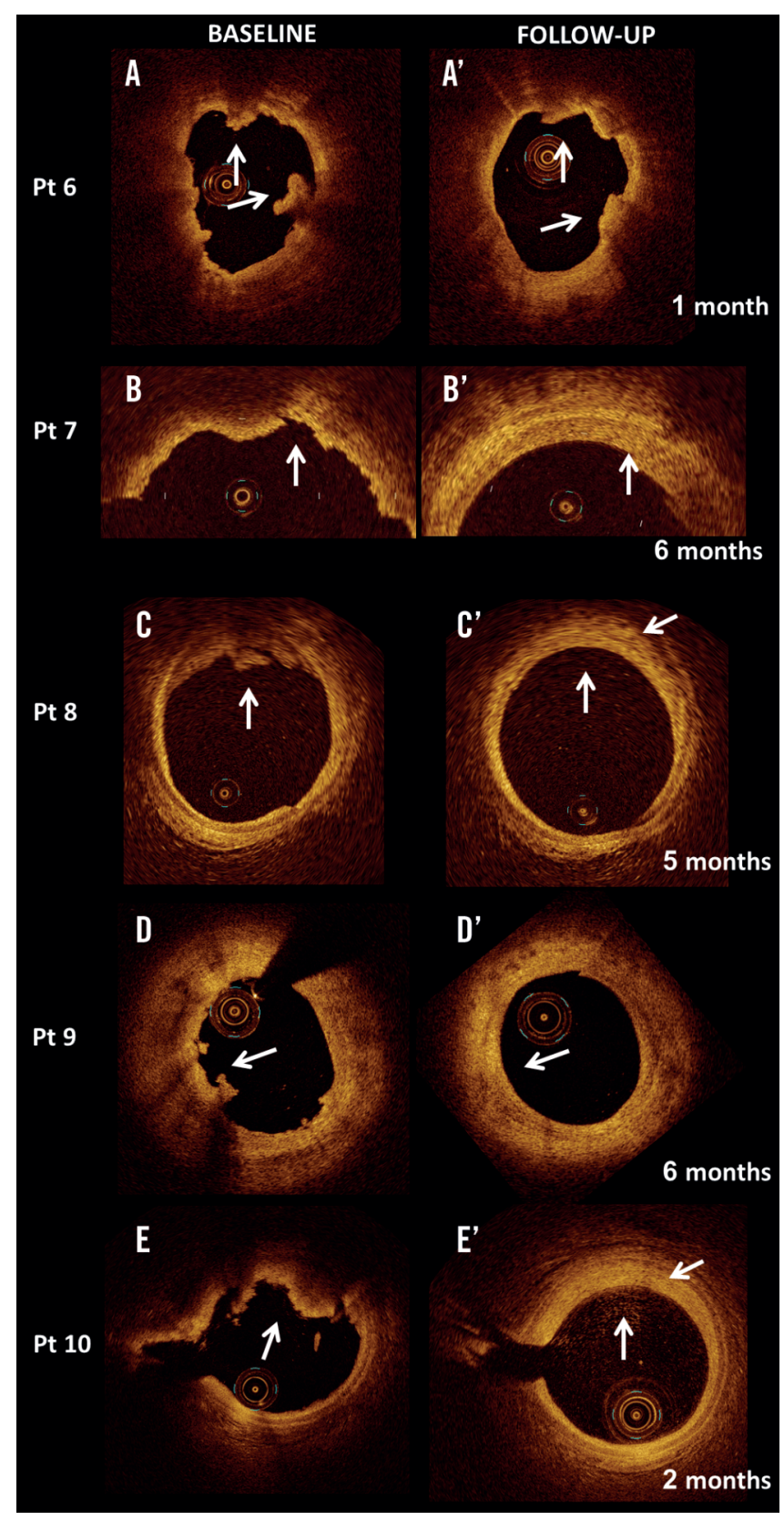

Figure 2. OCT assessment of culprit lesions with intact fibrous cap (IFC) at baseline and inherent changes over time. A-A'. Patient with STEMI who had an early 28-day follow-up assessment. In the acute phase OCT shows multiple thrombus appositions (arrows in the left panel), which are still seen at follow-up (arrows in the right panel). The remaining panels refer to the four culprit lesions with IFC (B, $C, D, E)$, which were studied in the follow-up time period ( $B$ ', $C$ ', $\left.D^{\prime}, E^{\prime}\right)$ of between 42 and 187 days. Irregular contours due to thrombus apposition are visible in the acute phase (arrows in the left panel) and become smooth during follow-up. Of note, signs of organised thrombus can be seen at follow-up (arrows in the right panel) with a two-layer appearance and a rim of circumferential transition exhibiting a low backscatter.

have identified multiple ruptured plaques have consistently implied that the plaque ulceration is a marker of acute plaque instability ${ }^{10}$. However, our preliminary OCT data suggest that the unhealed ulcers may not necessarily imply clinical instability, especially in the presence of effective antiplatelet therapy. Our findings are supported by a recent observation, showing that the aspect of quiescent plaque rupture remains stable during long-term follow-up ${ }^{11}$, and that finding multiple ruptured plaques may not directly translate into multilocus coronary instability.

Finally, the present study suggests that patients with non-critically narrowed culprit plaques could be treated simply with thrombus removal to reduce the risk of no-reflow related to balloon angioplasty and stent deployment.

\section{Limitations}

The limitations of this study include the low number of patients, the different intervals of time which elapsed between baseline OCT evaluation and follow-up as well as the non-identical treatment options in the 10 patients, in whom, however, dissolution of the thrombus was equally and successfully achieved.

The penetration capability of OCT limits the assessment of the deeper portion of culprit plaques, particularly in the presence of superficial components which can attenuate the signal ${ }^{2,4}$.

\section{Conclusions}

The preliminary data of this hypothesis-generating study indicate that, in ACS patients with mildly narrowed culprit plaques with RFC, the cavity may persist for months and may gradually develop neointima repair. In the culprit plaques with IFC, the residual thrombus is probably incorporated into the plaque, generating the double layer seen in OCT images.

\section{Impact on daily practice}

This serial OCT study was carried out in patients with ACS, treated with thrombus removal without the adoption of technical solutions that affect the mechanisms of plaque repair, such as balloon dilatation and stenting. Plaque cavities in ruptured fibrous cap lesions tend to remain in contact with the lumen, even several months after an acute coronary event, while, in the presence of intact fibrous cap, residual thrombotic material tends to organise and be incorporated in the plaque. Importantly, in both cases, plaque size does not increase significantly with respect to baseline. Therefore, in daily practice, our results can support a strategy of thrombus removal only, without stent implantation to treat culprit lesions, regardless of the mechanism of local thrombosis. Furthermore, plaques with signs of ulceration and without local thrombosis on OCT should be considered quiescent plaques that do not require any specific treatment.

\section{Conflict of interest statement}

The authors have no conflicts of interest to declare.

\section{References}

1. Maseri A, Fuster V. Is there a vulnerable plaque? Circulation. 2003;107:2068-71. 
2. Prati F, Regar E, Mintz GS, Arbustini E, Di Mario C, Jang IK, Akasaka T, Costa M, Guagliumi G, Grube E, Ozaki Y, Pinto F, Serruys PW; Expert's OCT Review Document. Expert review document on methodology, terminology, and clinical applications of optical coherence tomography: physical principles, methodology of image acquisition, and clinical application for assessment of coronary arteries and atherosclerosis. Eur Heart J. 2010;31:401-15.

3. Prati F, Petronio S, Van Boven AJ, Tendera M, De Luca L, de Belder MA, Galassi AR, Imola F, Montalescot G, Peruga JZ, Barnathan ES, Ellis S, Savonitto S; FINESSE-ANGIO substudy investigators. Evaluation of infarct-related coronary artery patency and microcirculatory function after facilitated percutaneous primary coronary angioplasty: the FINESSE-ANGIO (Facilitated Intervention With Enhanced Reperfusion Speed to Stop EventsAngiographic) study. JACC Cardiovasc Interv. 2010;3:1284-91.

4. Prati F, Guagliumi G, Mintz GS, Costa M, Regar E, Akasaka T, Barlis P, Tearney GJ, Jang IK, Arbustini E, Bezerra HG, Ozaki Y, Bruining N, Dudek D, Radu M, Erglis A, Motreff P, Alfonso F, Toutouzas K, Gonzalo N, Tamburino C, Adriaenssens T, Pinto F, Serruys PW, Di Mario C; Expert's OCT Review Document. Expert review document part 2: methodology, terminology and clinical applications of optical coherence tomography for the assessment of interventional procedures. Eur Heart J. 2012;33:2513-20.
5. Bezerra HG, Attizzani GF, Costa MA. Three-dimensional imaging of fibrous cap by frequency-domain optical coherence tomography. Catheter Cardiovasc Interv. 2013;81:547-9.

6. Virmani R, Kolodgie FD, Burke AP, Farb A, Schwartz SM. Lessons from sudden coronary death: a comprehensive morphological classification scheme for atherosclerotic lesions. Arterioscler Thromb Vasc Biol. 2000;20:1262-75.

7. Goldstein JA, Demetriou D, Grines CL, Pica M, Shoukfeh M, O'Neill WW. Multiple complex coronary plaques in patients with acute myocardial infarction. $N$ Engl J Med. 2000;343:915-22.

8. Hong MK, Mintz GS, Lee CW, Kim YH, Lee SW, Song JM, Han KH, Kang DH, Song JK, Kim JJ, Park SW, Park SJ. Comparison of coronary plaque rupture between stable angina and acute myocardial infarction: a three-vessel intravascular ultrasound study in 235 patients. Circulation. 2004;110:928-33.

9. Buffon A, Biasucci LM, Liuzzo G, D’Onofrio G, Crea F, Maseri A. Widespread coronary inflammation in unstable angina. $N$ Engl J Med. 2002;347:5-12.

10. Mann J, Davies MJ. Mechanisms of progression in native coronary artery disease: role of healed plaque disruption. Heart. 1999;82:265-8.

11. Di Vito L, Prati F, Arbustini E, Crea F, Maseri A. A "stable" coronary plaque rupture documented by repeated OCT studies. JACC Cardiovasc Imaging. 2013;6:835-6. 